\title{
Flow Simulation And Analysis Of High-Power Flow Batteries
}

\author{
E. Knudsen ${ }^{\mathrm{a}, *}$, P. Albertus ${ }^{\mathrm{b}}$, K. T. Cho ${ }^{\mathrm{c}}$, A. Z. Weber ${ }^{\mathrm{d}}$, A. Kojic ${ }^{\mathrm{a}}$ \\ ${ }^{a}$ Bosch Research and Technology Center, Palo Alto CA 94304 \\ ${ }^{b}$ Advanced Research Projects Agency - Energy, Washington, DC 20585 \\ ${ }^{c}$ Northern Illinois University, Dept. of Mechanical Engineering, Dekalb, IL 60115 \\ ${ }^{d}$ Lawrence Berkeley National Laboratory, Berkeley CA 94720
}

\begin{abstract}
The cost of a flow battery system can be reduced by increasing its power density and thereby reducing its stack area. If per-pass utilizations are held constant, higher battery power densities can only be achieved using higher flow rates. Here, a 3D computational fluid dynamics model of a flow battery flow field and electrode is used to analyze the implications of increasing flow rates to high power density operating conditions. Interdigitated and serpentine designs, and cell sizes ranging from $10 \mathrm{~cm}^{2}$ to $400 \mathrm{~cm}^{2}$, are simulated. The results quantify the dependence of pressure loss on cell size and design, demonstrating that the details of the passages that distribute flow between individual channels and the inlet and outlet have a major impact on pressure losses in larger cells. Additionally, in-cell flow behavior is analyzed as a function of cell size and design. Flow structures are interrogated to show how and where electrode parameters influence pressure drops, and how regions where transport is slow are correlated with the presence of experimentally observed cell degradation.
\end{abstract}

\section{Introduction}

As the electricity share generated by intermittent sources such as solar and wind grows, increasing attention is being placed on energy storage technologies that can handle grid-scale demand. Flow batteries $[1,2,3,4,5]$ have been proposed as a means of addressing grid scale needs $[6,7,8]$ because their capacity can be increased simply by using larger active material storage tanks. However, these batteries are subject to a number of materials and engineering challenges that tend to increase system costs and inhibit realizability [8]. Many of the cost challenges can be addressed by moving towards higher power density stacks, which reduce the area and hence material required for a given power output. But, such a move requires special consideration of how higher power densities affect design parameters such as flow rates, electrode thicknesses and pumping losses. These considerations must include scalability, since industrial flow batteries

\footnotetext{
* Corresponding author.

Email address: ewk@alumni.stanford.edu (E. Knudsen)
} 
may use cells with active areas on the order of $1000 \mathrm{~cm}^{2}$ [5]. This paper considers the flow transport physics associated with the higher flow rates required for higher power densities.

Two flow transport processes particularly influence the performance of a flow battery cell. First, the pressure drop required to move reactants throughout the system is a load that reduces the system efficiency. Minimizing this pressure drop will allow more of the cell's energy to be devoted to useful work. Second, the velocity distribution within a flow field and electrode has a direct impact on mass transport to the reaction sites on the surface of the porous electrodes. For example, if a flow dead zone occurs within a porous electrode then mass transport will be supported only by diffusion and migration. This can significantly reduce the local current density relative to other regions where reactants are being actively supplied through convection. The presence of flow dead zones can also lead to localized degradation because these zones can foster local electrochemical or chemical conditions that drive unwanted processes (e.g., carbon oxidation). An example of such degradation in a $50 \mathrm{~cm}^{2}$ variant of an experimental $\mathrm{H}_{2} / \mathrm{Br}_{2}$ flow cell $[8,9]$ is shown below in Fig. 8a. Similarly, neutron imaging has indicated [10] that transport limitations occur around complex features in fuel cell flow fields. The importance of reactant transport in flow batteries motivates the need for a detailed understanding of fluid flow within these cells. Here, three-dimensional (3D) computational fluid dynamics (CFD) tools are used to advance this understanding.

The application of CFD modeling to flow batteries is limited, but the technique has been used to study flow through other electrochemical systems such as fuel cells [11, 12]. For example, a series of studies have investigated transport in Proton-Exchange Membrane Fuel Cell (PEMFC) settings [13, 14, 15, 16, 17, 18]. This body of work analyzed representative elements from PEMFCs, such as a set of two individual flow channels or an extracted section of a 3D cell geometry. Findings include the importance of 3D flow effects, analyses of where phase change in PEMFCs is important, and demonstrations of the ability to predict relationships between transport behavior and electrochemical performance. Because only representative cell elements were considered, however, pressure drops across entire cells and the influence of full flow field design parameters could not be assessed.

A second series of studies [19, 20, 21, 22, 23] used CFD techniques to simulate full 3D PEMFCs. These studies examined polarization curves, pressure drops, and a number of cell design parameters. Furthermore, a detailed review of how a series of 3D flow field parameters influence PEMFC performance was performed by Manso et al. [24]. Channel design, flow direction, channel length and number, channel cross section shapes, and baffle designs were all considered. For the most part, the active cell areas being considered in these full cell efforts were below $25 \mathrm{~cm}^{2}$. The work of Kvesić et al. [22] was an exception, in that they simulated a 5 cell PEMFC stack with individual cell areas of $200 \mathrm{~cm}^{2}$. Their study, however, invoked a lumped porous model in which the geometric details of the flow fields in each cell were not resolved. Full simulations of the 
large cell areas that are needed for industrial applications and high power densities, and the consideration of scalability, was not in focus.

While some analysis from PEMFC literature is directly applicable to Vanadium / Vanadium [25], Hydrogen / Bromine $[8,9,26]$, and other redox flow batteries, important differences between PEMFCs and flow batteries exist. These differences include the use of single phase transport in many flow battery half cells, and they motivate the consideration of designs specific to flow battery requirements. While less common, CFD models of flow battery systems have been developed by a few groups. Latha and Jayanti [27] analyzed flow battery hydrodynamics using both experimental and 3D CFD analyses. They compared pressure drops and velocities in representative sections of $\sim 40 \mathrm{~cm}^{2}$ interdigitated and serpentine flow field designs, and particularly noted why these designs might be viewed differently from fuel cell and from flow battery perspectives. Brunini et al. [28] developed a 3D single channel model of a novel semi-solid variety of flow battery [29] in which both electrically conductive and solid, ion accepting particles are suspended in a transported liquid medium. Their model was used to investigate how the dependence of the voltage on the state-of-charge influences system performance. The group also developed a 2D semi-solid flow battery CFD model [30].

This paper seeks to build upon existing flow battery modeling literature by considering full cell designs with their associated flow delivery and removal passages, and by considering the cell areas (up to $400 \mathrm{~cm}^{2}$ ), scalability concerns, and flow rates that are relevant for industrial high power density operating conditions. This introduction serves as section 1 of the paper. Section 2 describes the different flow field designs that are considered. The governing equations and computational infrastructure used for the CFD calculations are presented in section 3. Computational results are shown in section 4, and the paper's conclusions are summarized in section 5 .

\section{Simulated cases}

The cases simulated in this work are variants of the $\mathrm{H}_{2} / \mathrm{Br}_{2}$ cell studied by Cho et al. [8, 9]. This cell was experimentally tested using both $10 \mathrm{~cm}^{2}$ flow-through and $10 \mathrm{~cm}^{2}$ and $50 \mathrm{~cm}^{2}$ flow-by serpentine flow fields. Only the liquid $\left(\mathrm{Br}_{2}\right)$ side of the $\mathrm{H}_{2} / \mathrm{Br}_{2}$ cell is simulated here, since gaseous $\mathrm{H}_{2}$ transport is expected to be less of a limiting factor than aqueous $\mathrm{Br}_{2}$ solution transport.

Flow-through electrode designs can be used for flow batteries when low current densities are acceptable. In these flow-through designs, no channels are made in the battery flow fields and fluid travels across the entire area of the cell through the porous electrode. When current densities are low, flow rates are also relatively low and the pressure drops across flow-through designs are acceptable. Such designs are not appropriate for higher current densities, however, because higher flow rates are required. These higher flow rates can only 
be achieved in a flow through electrode with large pressure gradients that are driven by pumping systems which consume significant energy. This observation assumes that all flow in a flow-through design passes through an electrode of uniform porosity. More elaborate flow-through-like designs with spatially varying porosity have been proposed, but are not considered here.

The goal of minimizing pressure losses while supplying sufficient reactants to the electrode forces the consideration of flow-by designs. In these designs, open channels are cut into a solid plate that is placed adjacent to the electrode. The open channels provide fluid with lower resistance paths across the cell area. For example, Darling and Perry [31] experimentally compared the performance of a flow-through Vanadium flow battery with that of two flow-by designs. They found that the flow-through design would lead to significantly larger pressure drops than the flow by designs as the cell size was scaled up toward industrial applicability. They also analyzed sensitivities to the transport phenomena that must be accounted for when switching between flow field designs.

Five flow-by designs that include three different cell sizes are simulated. Figure 1 depicts the selected flow field geometries. The first two are serpentine channel designs: one $10 \mathrm{~cm}^{2}$ design utilizing a single channel (Fig. 1a), and one $50 \mathrm{~cm}^{2}$ design utilizing four channels (Fig. 1b). The channel in the $10 \mathrm{~cm}^{2}$ serpentine design consists of 20 long passages connected by bends. The cross section of this channel is 1.016 $\mathrm{mm}$ high and $0.7874 \mathrm{~mm}$ wide. The spacing between channels is $0.853 \mathrm{~mm}$. The dimensions of the 10 $\mathrm{cm}^{2}$ serpentine design were chosen to mimic the experimental flow fields from [8] and [9], which employed hardware manufactured by Fuel Cell Technologies, Inc. The four channels in the $50 \mathrm{~cm}^{2}$ serpentine design all consist of 11 long passages (44 in total) connected by bends. The cross section of each channel is the same, measuring $0.795 \mathrm{~mm}$ high and $0.795 \mathrm{~mm}$ wide. The spacing between channels is $0.795 \mathrm{~mm}$.

The next three designs employ interdigitated flow fields (idffs). The dimensions of the interdigitated channels were chosen to ensure similarity with the serpentine hardware specifications. The first two interdigitated designs both have active cell areas of $50 \mathrm{~cm}^{2}$, but different spacings between channels. In the loosely spaced case (Fig. 1c), the distance between flow channels is $4.0 \mathrm{~mm}$. This design has 15 channels in total, and each channel has a width and height of $0.8 \mathrm{~mm}$. In the tightly spaced design (Fig. 1d), the distance between channels is $0.8 \mathrm{~mm}$. This design's 44 channels also have widths and heights of $0.8 \mathrm{~mm}$. The third interdigitated geometry has a larger active cell area of $400 \mathrm{~cm}^{2}$ (Fig. 1e). This cell area was considered in an effort to approach more industrially relevant cell sizes. The design is characterized by a relatively loose channel spacing of $3.2 \mathrm{~mm}$. The 50 channels have widths and heights of $0.8 \mathrm{~mm}$.

Three different electrode thicknesses are used in the simulations. As shown with a $50 \mathrm{~cm}^{2}$ loose interdigitated flow field in Fig. If - 1h, these electrode thicknesses are $0.4 \mathrm{~mm}, 1.2 \mathrm{~mm}$, and $2.4 \mathrm{~mm}$. The last of these values is too thick to be considered for use in a practical device due to ohmic drops. It is helpful, 
however, for exposing the electrode's influence on hydrodynamics.

The liquid half cell hydrodynamic systems are simulated using area specific flow rates of between

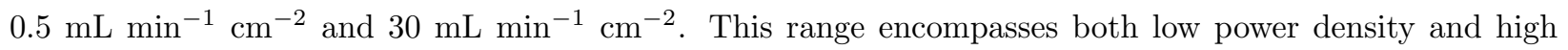
power density operating conditions. Water is used as the working fluid in all simulations to represent the aqueous Bromine solution that passes through one side of an $\mathrm{H}_{2} / \mathrm{Br}_{2}$ flow battery. Actual electrolyte fluids may have higher viscosities $[31,32,33,34]$, which would further increase the pressure drops presented in this analysis.

Representative Reynolds numbers describing flow through individual channels are shown in Table 1. This table assumes the total flow is equally distributed amongst the channels. For the serpentine designs, the table also assumes that $60 \%$ of the total flow passes through the open channels, with the remainder passing through the electrode (see Fig. 4c for details regarding these flux splits). For the interdigitated designs, the table assumes that $100 \%$ of the flow passes through half of the total number of channels (the flow passes from the inlet channels to the outlet channels through the electrode). In reality, the velocities in the channels can deviate significantly (both higher and lower) from the values implied by Table 1, and the tabulated Reynolds numbers only provide baseline information. The values in Table 1 show that for many of the half cell configurations and flow rates the flow is laminar. But, because of local deviations that may change the velocity by an integer multiple, for some half cell configurations and flow rates turbulence can occur. Additionally, turbulence may be found in the conduits connecting the inlet and the outlet to individual channels. In these conduits Reynolds numbers can be even larger than in the channels.

Data from Gostick et al. [35] is the source of the carbon electrode material's permeability and porosity. The permeability of the electrode is set as $\kappa=1 \times 10^{-11} \mathrm{~m}^{2}$ and the porosity is set as $\gamma=0.9$. To understand the influence of the electrode permeability, additional simulations are performed using values of $\kappa=1 \times 10^{-10} \mathrm{~m}^{2}$ and $\kappa=1 \times 10^{-9} \mathrm{~m}^{2}$. This range is quite wide, but it clearly exposes trends and it encompasses the electrode permeabilities that were simulated in [27]. In a real cell, permeability is expected to depend on the compression applied to the porous electrode and therefore may vary spatially. 


\section{Simulation methodology}

\subsection{Governing equations}

Flow in the electrodes and channels is solved using the steady, incompressible, Reynolds Averaged NavierStokes equations with porous media transport terms included,

$$
\begin{array}{r}
\frac{\partial}{\partial x_{j}}\left(\gamma \overline{\rho u}_{j}\right)=0 \\
\frac{\partial}{\partial x_{j}}\left(\gamma \overline{\rho u}_{i} \bar{u}_{j}\right)=-\gamma \frac{\partial}{\partial x_{i}}(\bar{p})+\frac{\partial}{\partial x_{j}}\left(\gamma\left(\bar{\tau}_{i j}+\bar{\sigma}_{i j}\right)\right)-\frac{\bar{\rho} \nu}{\kappa} \bar{u}_{i},
\end{array}
$$

where $u_{j}$ is the velocity in the $j^{t h}$ direction, $\rho$ is the density, $p$ is the pressure, $\gamma$ is the porosity, $\kappa$ is the permeability, and $\nu$ is the kinematic viscosity. The overline symbol $\left(^{-}\right)$denotes ensemble averaging. The porosity $\gamma$ is constant in both the open channel region and the electrode region, so that its placement inside gradient operators is only relevant at the channel / electrode interface. The viscous stress tensor $\tau_{i j}$ and the Reynolds stress tensor, $\sigma_{i j}$, are,

$$
\begin{array}{r}
\bar{\tau}_{i j}=\bar{\rho} \nu\left[\left(\frac{\partial \bar{u}_{i}}{\partial x_{j}}+\frac{\partial \bar{u}_{j}}{\partial x_{i}}\right)-\frac{2}{3} \delta_{i j} \frac{\partial \bar{u}_{k}}{\partial x_{k}}\right], \\
\bar{\sigma}_{i j}=\overline{\rho u}_{i} \bar{u}_{j}-\overline{\rho u_{i} u_{j}}
\end{array}
$$

The Reynolds numbers in many flow battery passages are low, indicating that the flow is laminar and no turbulence model is needed. At high flow rates, however, velocities in open channel regions may become large enough to reach Reynolds numbers associated with transition or weak turbulence. The ensemble averaged form of the Navier-Stokes equations is solved to allow for this possibility. A realizable $k$ - $\epsilon$ turbulence model $[36,37,38]$ is used to close the Reynolds stress tensor $\bar{\sigma}_{i j}$ in this ensemble averaged framework. The use of this turbulence closure does influence the quantitative simulation results reported below.

\subsection{Numerics}

The ANSYS Fluent [39] software package was used to solve the governing equations, and an incompressible, constant density, implicit formulation was chosen for this study. Second order gradient operators were used for the continuity and momentum equations (Eqs. (1)-(2)), and first order gradient operators were used to solve the transport equations for the $\bar{k}$ and $\bar{\epsilon}$ variables that are needed to close the Reynolds stress $\bar{\sigma}_{i j}$. Fluent's standard wall treatment was chosen for use with the realizable $k$ - $\epsilon$ turbulence model. Individual cases were run on between 100 and 300 cpus, and converged after a time period of between twenty minutes and an hour and a half. 


\subsection{Boundary Conditions}

Simulation boundary conditions were prescribed as follows. A constant mass flow rate was specified at the inlet plane of the cell, and an outflow condition (a convective boundary condition that adjusts the mass flow to ensure conservation) was specified at the outlet plane. The magnitude of the inlet mass flow rate changed from run to run as different cell operating conditions were investigated. The specified mass flow rates can be used to calculate bulk velocities in the inlet and outlet pipes of each cell design. For example, in the $10 \mathrm{~cm}^{2}$ serpentine design the inlet velocity varies between $0.086 \mathrm{~m} \mathrm{~s}^{-1}$ and $0.86 \mathrm{~m} \mathrm{~s}^{-1}$ as the flow rate changes from $1 \mathrm{~mL} \mathrm{~min}{ }^{-1} \mathrm{~cm}^{-2}$ to $10 \mathrm{~mL} \mathrm{~min}^{-1} \mathrm{~cm}^{-2}$. In the $400 \mathrm{~cm}^{2}$ interdigitated design, the velocity varies between $0.24 \mathrm{~m} \mathrm{~s}^{-1}$ and $2.4 \mathrm{~m} \mathrm{~s}^{-1}$ as the flow rate spans this same range of $1 \mathrm{~mL} \mathrm{~min}-1 \mathrm{~cm}^{-2}$ to

$10 \mathrm{~mL} \mathrm{~min}-1 \mathrm{~cm}^{-2}$. The enforcement of mass conservation ensures that the bulk velocity in the outlet pipe is equivalent to that of the inlet pipe.

A zero velocity (no-slip) condition was applied on all of the flow channel walls, and on the sides of the electrode. The model neglects mass flux through the membrane separator, so a zero velocity condition was applied to the electrode face adjacent to the separator (the hidden face in Figs. 1a - 1e). Faces that connected the open channels and the electrode were treated as normal internal flow faces, with porous media modeling applied only to the flow on the electrode side. Zero velocity boundary conditions were applied to the faces on the top of the electrode (opposite the membrane separator) that did not connect to an open channel.

\subsection{Model Assumptions}

The chosen modeling approach invokes several assumptions. Unsteady flow effects are neglected, as is mass transfer across the membrane separator. The assumption of constant fluid properties neglects viscosity changes due to the electrolyte's changing composition during cycling. Porosity and permeability are assumed constant in the model, while in reality mechanical compression effects and material inhomogeneities may produce spatial variability. And, it is assumed the $k-\epsilon$ turbulence model adequately describes the transitional and weakly turbulent flow that may develop in localized regions of a cell.

The assumption of zero mass flux through the membrane separator neglects physical processes such as transport of the electrochemically active ion species through the membrane, and the undesired crossover of the electrolyte material. These processes are left untreated because their associated mass flow rates are small relative to the liquid mass flux through the cell. For example, in a $50 \mathrm{~cm}^{2} \mathrm{H}_{2} / \mathrm{Br}_{2}$ cell operating at a high power density of $0.5 \mathrm{~A} \mathrm{~cm}^{-2}$, the mass flux of $\mathrm{H}^{+}$protons across the membrane is $\sim 2.6 \times 10^{-7} \mathrm{~kg} \mathrm{~s}^{-1}$. A corresponding liquid mass flux through the cell at a high power density flow rate of $10 \mathrm{~mL} \mathrm{~min}{ }^{-1} \mathrm{~cm}^{2}$ is $\sim 8.3 \times 10^{-3} \mathrm{~kg} \mathrm{~s}^{-1}$, or more than four orders of magnitude larger. Furthermore, crossover transport probably does not significantly depend on macro-scale flow transport. Tucker et al. [40] and Cho et al. [41] suggest 
that in $\mathrm{H}_{2} / \mathrm{Br}_{2}$ flow cells crossover is primarily influenced by electro-osmosis. Diffusion and pressure-driven permeation play important but secondary roles. Electro-osmosis occurs on micro-scales in the membrane separator where convection is vanishingly small. As long as the macro-scale flow keeps the membrane wetted, details of the macro scale flow are not expected to influence electro-osmosis or diffusion.

Simpler flow models that invoke additional assumptions have been developed in other studies. As referenced in section 1, Kvesić et al. [22] used a lumped porous model that did not resolve all geometric details of the cell. Prasad et al. [42] and Jyothi Latha and Jayanti [27] created flow network models that treat flow channel and porous media sections as resistors in a voltage / current analogy. These models were shown to reproduce experimental measurements from a 4 channel interdigitated flow cell. While more expensive, a model that resolves 3D cell geometry offers the advantage of capturing the non-linear flow physics associated with recirculation and inertia around channel bends, and with turbulence. For example, pressure losses through channel bends can be more accurately described when the flow field and momentum transfer through the turn is spatially resolved.

\subsection{Meshes}

Meshes were created for each of the flow battery half cells in Fig. 1 using OpenFOAM's SnappyHexMesh [43] tool. The resulting cell counts are listed in Table 2. In all of the meshes used in the results section below, individual flow channels are discretized by placing at least 8 cells across both non-streamwise directions. Multiple entries in the third column of Table 2 indicate that mesh sensitivity was tested by running a single operating point using different mesh resolutions. For example, the $50 \mathrm{~cm}^{2}$ serpentine mesh was simulated using mesh sizes ranging from 6.9 million cells to 20.2 million cells. The calculated pressure difference across this particular half cell changed by several percent as the mesh resolution was adjusted. These mesh sensitivities are negligible relative to the changes in pressure drops produced by even small changes in the cell design or flow rate.

\section{Results}

Pressure drops across half cells are presented first, as a function of system parameters. Second, the flux of reactants across the interface between the flow channels and the electrode is analyzed. Third, the flow patterns are visualized to study electrode transport processes in more detail. Finally, the existence of flow dead zones that can contribute to cell degradation is investigated.

\subsection{Pressure losses}

Pressure drops across the half cells are plotted in Fig. 2. Figure 2a shows the pressure drop versus the area specific flow rate, $q$, for all flow field designs paired with a $0.4 \mathrm{~mm}$ electrode. For reference, linear (i.e. 
$\left.q^{1}\right)$ and quadratic $\left(q^{2}\right)$ scaling relationships are drawn as thin black lines at the top of the figure. In the limit of negligible convection and diffusion, the momentum transport equation (Eq. (2)) reduces to Darcy's law,

$$
\frac{\partial}{\partial x_{i}}(\bar{p})=-\frac{\bar{\rho} \nu}{\gamma \kappa} \bar{u}_{i}
$$

and the pressure drop scales linearly with flow rate. In typical low Reynolds number channel flow, pressure drops also scale linearly with flow rate. At higher Reynolds numbers, however, the scaling power increases and the flow rate dependence approaches quadratic. A scaling power of greater than one can additionally be expected in flow around channel bends. The interaction of these relationships produces the complex behavior in Fig. 2, where scaling powers vary between one and two as a function of design and flow rate. For example, the scaling power of the interdigitated designs increases with flow, nearly reaching quadratic behavior at high $q$ values. Conversely, the serpentine designs exhibit a more constant and lower magnitude scaling power. Consequently, pressure losses through flow channels are more significant in the interdigitated designs, while losses through electrodes are more significant in the serpentine designs.

Relationships between flow field design and pressure losses can be investigated by comparing the cases with cell areas of $50 \mathrm{~cm}^{2}$ in Fig. 2a. The serpentine design produces the largest pressure drop, and the smallest drop occurs in the tight interdigitated design. This trend is consistent with the data of Latha and Jayanti [27]. At high flow rates, the drops across the interdigitated designs cease to depend on channel spacing. Their quadratic scaling behavior and this lack of channel spacing dependence suggest that high flow rate pressure drops in the interdigitated designs are caused by a combination of the increased friction in the open channel flow and the pressure needed to force fluid through the upstream distribution and downstream collection systems.

Figure $2 \mathrm{~b}$ shows how pressure loss is influenced by electrode thickness, while Fig. 2c shows the influence of electrode permeability. Only data from cells with $50 \mathrm{~cm}^{2}$ areas are shown. Symbols denote the electrode thickness and permeability, and line colors denote the flow field designs. Trends from these figures are similar in that the pressure loss in the serpentine designs is strongly sensitive to the electrode parameters, while the loss in the interdigitated designs is not. This further indicates that flow through the electrode is a relatively more important driver of the serpentine pressure drop than the interdigitated drop.

Figure 2a can also be used to examine how pressure drops scale with cell area. The $400 \mathrm{~cm}^{2}$ loose interdigitated design produces large pressure losses, even after the flow rate has been normalized by the cell area. As the area increases, the mean velocity in an individual interdigitated channel must increase to keep the area specific flow rate constant. Pressure losses increase in response. Scaling analyses must carefully account for these non-linear geometric and flow effects when predicting the behavior of industrially relevant 
cells that may have active areas as large as $1000 \mathrm{~cm}^{2}$ [5]. Other important influences on scalability include the pressure required to move reactants through and out of the large distribution channels (the especially wide channels oriented perpendicular to the bulk flow direction in Fig. 1e) that connect the inlet and outlet pipes to the individual flow channels. Unlike the flow rate, the size of these distribution channels varies only weakly with cell area. This creates increasingly large velocities and pressure losses in the main channels at higher flow rates. A simple extrapolation of results obtained for cells with small active areas may not capture these effects.

A typical area specific flow rate target for a high power density flow battery is $10 \mathrm{~mL} \mathrm{~min}{ }^{-1} \mathrm{~cm}^{2}$, and a typical targeted pressure drop is $\sim 1$ atm or less. Figure 2a indicates that, at a flow rate of $10 \mathrm{~mL} \mathrm{~min}{ }^{-1} \mathrm{~cm}^{2}$, changing the design of a $50 \mathrm{~cm}^{2}$ cell from a serpentine layout to an interdigitated layout would keep the pressure drop within an acceptable window. In a more industrially relevant $400 \mathrm{~cm}^{2}$ cell, however, the pressure drop significantly exceeds $1 \mathrm{~atm}$ at this target. This motivates the need for additional engineering that can further limit pressure drops.

Furthermore, in many flow battery chemistries the viscosity of the electrolyte can be larger than the viscosity of water used in this model [31, 32, 33, 34]. Higher viscosities will further drive pressure losses, but probably with only a sub-linear viscosity scaling. In both laminar channel flow and porous media flow, the pressure drop should scale linearly with viscosity (see Eq. (5)), whereas in turbulent channel flow and flow through channel bends the scaling power is significantly smaller. Detailed flow models are needed to understand the relative contribution of each loss type.

Further insight into cell engineering needs can be gained by examining pressure drops across specific flow pathways in the $400 \mathrm{~cm}^{2}$ design. These pressure drops are presented in Fig. 3, where data is taken from a single cut plane (Fig. 3a) located halfway up the open channels. The magnitudes of the pressure drops along individual pathways are tabulated in Fig. 3b. For example, the pressure drop between points $\mathrm{F}$ and $\mathrm{G}$ of the cut plane is $17 \%$ of the pressure drop across the entire half cell. At high flow rates, then, a significant fraction of the pressure head is needed to move fluid from the main inlet pipe into the open channels. Similarly large pressure losses occur as the flow moves from the individual flow channel outlets to the pipe through which all flow exits the half cell. Modifying the geometry of the inlet and outlet pipes, and of the large cross channels that transport reactants to and from individual flow channels, is therefore a realistic option for reducing pressure drops in industrially sized, high power designs.

\subsection{Flux pathways}

Understanding how reactants are brought to electrochemically active sites requires understanding fluxes between open flow channels and the porous electrode. These fluxes are fundamentally different in the 
serpentine and interdigitated designs. In interdigitated designs, half of the channels only transport fresh reactants into the electrode, while the other half only transport products out of the electrode. In serpentine designs a single channel may alternate between transporting reactant mixture into and out of the electrode.

Fluxes in the serpentine designs are analyzed first. Figures $4 \mathrm{a}$ and $4 \mathrm{~b}$ show planes in the $10 \mathrm{~cm}^{2}$ and $50 \mathrm{~cm}^{2}$ serpentine cells from which data is extracted. These planes (colored red) are perpendicular to the direction of bulk fluid flow, and are separated into two regions: one consisting of material within the open flow channels, and the other consisting of material within the electrode. The normal flux through each of these areas is computed to determine how much flow passes through the open channels and how much passes through the electrode. The planes were prescribed to cut across channel bends, rather than across long channel sections, so that open channel flow would be moving normal to the planes.

Fluxes through the cut planes in Figs. $4 \mathrm{a}$ and $4 \mathrm{~b}$ are plotted in Fig. $4 \mathrm{c}$ as a function of the specific flow rate. $50 \mathrm{~cm}^{2}$ cell data is calculated for all three electrode thicknesses, while $10 \mathrm{~cm}^{2}$ cell data is shown only for a $0.4 \mathrm{~mm}$ electrode. The Fig. $4 \mathrm{c}$ data describes the percentage of the total flux that passes through the electrode, with the remainder passing through the open channels. The split of flow between these pathways depends strongly on the flow rate, and the material passing through the electrode varies from $20 \%$ to $60 \%$ as the mass flow increases. A physical mechanism contributing to this behavior is the scaling relationship between pressure and flow rate. Pressure drops in the open channels begin to scale quadratically at high flow rates, while pressure drops in the electrode continue to scale linearly. The relative resistance of the electrode therefore decreases at high power density conditions. This forces an increasing percentage of the reactant stream through the electrode. This observation might be particularly utilized in a flow battery's control system, for example by periodically flushing used reactants from the system with short flow rate pulses.

\subsection{Flow visualization}

Several half cell flow fields are visualized to further understand how transport processes depend on design. Velocities from the $10 \mathrm{~cm}^{2}$ serpentine cell are shown in Fig. 5. The contours in Figs. 5a - 5c indicate standard channel flow, with some added vortical effects visible around channel bends in the out-of-plane velocities (Fig. 5c). Flux into the electrode is not distinguishable at these contour ranges and in a plane that is relatively far from the electrode interface. Figures $5 \mathrm{~d}-5 \mathrm{f}$, however, reveal interesting features of transport within the electrode. In-plane flow largely follows the channel paths, as seen in the oscillating pattern of positive and negative velocity in Fig. 5d. And, Fig. $5 \mathrm{f}$ directly shows the movement of reactants into and out of the electrode. Reactants tend to be pushed into the electrode (blue coloring in Fig. 5f) below the 'downstream' half of flow channel bends, and to be pushed back into the channels (red coloring) below the 'upstream' half of flow channel bends. This behavior is driven by the pressure differential between adjacent 
open channels. As flow approaches the upstream half of a channel bend, the path of least pressure resistance is to continue in the open channel around the bend. After fluid rounds the bend, however, it can only reach the adjacent bend through an open channel by twice traversing the entire width of the flow field. An alternative path is to move only a single channel width through the electrode, and into the next bend. Although this alternative path crosses porous media, its length is very short compared to the open channel path. Flow therefore tends to push into the electrode in the downstream half of channel bends, and to rise back into the channels in the upstream half of the adjacent bend.

Velocity contours from the $400 \mathrm{~cm}^{2}$ interdigitated flow field are shown in Fig. 6. Large scale asymmetries are observed in the open channels in Figs. 6a - 6c, with flow traveling most quickly through the channels at the center of the field. This indicates significant pressure resistance from the flow through the horizontal ( $\mathrm{x}$ direction) distribution channel. Velocities in the electrode are again more interesting because they highlight important transport processes. The cross-channel velocity component in Fig. 6d demonstrates the bifurcation of reactant flow into the electrode. Reactants pushed in from the right half of a channel are convected toward the nearest channel to the right, and reactants pushed in from the left half are convected toward the nearest channel to the left. A comparison of Figs. 6d and 6e additionally indicates this cross channel convection is much stronger than convection in the channel aligned direction.

Flow is also visualized on a set of planes that cut through the open channels and the electrode simultaneously. Velocities from a $400 \mathrm{~cm}^{2}$ loose interdigitated simulation are shown on these planes in Fig. 7 . There, cross channel (x) flow exhibits alternating positive and negative bands in regions between channels, confirming how it laterally traverses the electrode to reach the nearest open channel. Results from cuts through other cases indicate that this behavior is general: fluid in the interdigitated designs tends to move laterally after pushing into the electrode. In the $400 \mathrm{~cm}^{2}$ contours the color range in the channel aligned plots (Figs. 7b - 7d) is set to reveal electrode flow, so the relatively fast flow through the open channels saturates the color spectrum. This fast channel flow drives channel aligned (y) velocities in the electrode at locations just below the porous media interface. These channel aligned electrode velocities peak around $0.06 \mathrm{~m} \mathrm{~s}^{-1}$ in the immediate vicinity of the interface, but for the most part their magnitudes are much smaller. They can be compared to the the cross-channel (x) velocities in Figs. $7 \mathrm{~h}-7 \mathrm{j}$ to understand how flow behaves as a function of electrode depth. While flow is pulled in the channel aligned direction near the interface, it transitions to more distinctly lateral flow as it penetrates deeper into the electrode.

\subsection{Dead zones}

Developing a full understanding of cell degradation processes requires modeling scalar transport and electrochemical behavior in addition to flow transport. Nevertheless, flow modeling can provide insight into 
degradation drivers. Figure 8 compares a simulated result to an experimental observation of Cho et al. [8, 9]. The experimental images in Fig. 8a were taken after operating a $50 \mathrm{~cm}^{2}$ serpentine design at $60 \mathrm{~mA} \mathrm{~cm}-2$ for 100 hours between cutoff potentials of $1.25 \mathrm{~V}$ and $0.80 \mathrm{~V}$. The simulation images in Fig. 8b show velocity magnitudes on a cut plane located $0.3 \mathrm{~mm}$ below the electrode / flow channel interface, or $75 \%$ through the depth of the electrode.. The flow rate in both the experiment and simulation was $2 \mathrm{~mL} \mathrm{~min}{ }^{-1} \mathrm{~cm}^{-2}$ $\left(100 \mathrm{~mL} \mathrm{~min}^{-1}\right)$.

The contours in Fig. 8b depict a pattern of low speed flow in electrode regions underneath serpentine bends. Between these low speed regions, thin regions of high speed flow are found where reactants move through the electrode, as described in section 4.3. A comparison of Figs. 8a and 8b indicates significant correlation between regions where degradation is experimentally observed and regions where flow through the electrode is particularly slow. These regions are found in the immediate vicinity of the flow channel bends. Such correlation cannot be used to explain fully the observed degradation, but it is consistent with the idea that insufficient reactant transport to electrochemically active sites drives degradation.

\section{Conclusions}

3D computational fluid dynamics simulations have been used to investigate transport in flow battery half cells over a range of flow rates, channel designs, electrode thicknesses, and areas, including configurations relevant to high power density operation of large cells. The simulation data supports several conclusions. First, design of the flow delivery and distribution pathways that lead to individual interdigitated channels is a critical factor in the overall pressure drop observed in large interdigitated cells. Second, because pressure drops scale non-linearly with cell area and flow conditions, flow modeling is an important tool that can aid in the design of high performance cells. 3D flow models in particular offer the advantage of resolving pressure loss and transport mechanisms that can strongly influence cell performance. Third, results revealed that adequate pressure drops for industrially practical cell sizes of $1000 \mathrm{~cm}^{2}$ require further optimization beyond the designs considered here.

Additionally, flow structures in both electrodes and open channels were visualized through the use of numerous cut planes to understand the details of transport processes. Flow structure visualizations are a powerful, though primarily qualitative, tool because they provide important insight that may be used to improve cell design. For example, an understanding of local flow pathways informs how a flow field design should be altered to increase convection in one region, or slow it down in another.

Finally, conditions associated with the appearance of cell dead zones were investigated. In particular, it was demonstrated that regions of experimentally observed cell degradation can be correlated with regions 
where flow simulations predict particularly slow transport. This further motivates the use of these simulations for corrosion mitigation design modifications.

\section{Acknowledgements}

The authors gratefully acknowledge financial support from the Advanced Research Projects AgencyEnergy (ARPA-E) of the U.S. Department of Energy under contract no. DE-AC02-05CH11231 for LBNL and DE-ARDE-AR0000137 for Robert Bosch LLC, with cost share provided by Robert Bosch LLC. 
[1] C. Ponce de León, A. Frías-Ferrer, J. González-García, D. A. Szánto, and F. C. Walsh. Redox flow cells for energy conversion. J. Power Sources, 160(1):716-732, 2006.

[2] H. Chen, T. N. Cong, W. Yang, C. Tan, Y. Li, and Y. Ding. Progress in electrical energy storage system: A critical review. Prog. Natural Science, 19(3):291-312, 2009.

[3] A. Z. Weber, M. M. Mench, J. P. Meyers, P. N. Ross, J. T. Gostick, and Q. Liu. Redox flow batteries: a review. J. Applied Electrochemistry, 41(10):1137-1164, 2011.

[4] M. Skyllas-Kazacos, M. H. Chakrabarti, S. A. Hajimolana, F. S. Mjalli, and M. Saleem. Progress in flow battery research and development. J. Electrochem. Soc., 158(8):R55-R79, 2011.

[5] B. R. Chalamala, T. Soundappan, G. R. Fisher, M. R. Anstey, V. V. Viswanathan, and M. L. Perry. Redox flow batteries: An engineering perspective. Proc. IEEE, 102(6):976-999, 2014.

[6] A. Ipakchi and F. Albuyeh. Grid of the future. IEEE Power and Energy Magazine, 7(2):52-62, 2009.

[7] B. Dunn, H. Kamath, and J. M. Tarascon. Electrical energy storage for the grid: A battery of choices. Science, 334(6058):928-935, 2011.

[8] K. T. Cho, P. Ridgway, A. Z. Weber, S. Haussener, V. Battaglia, and V. Srinivasan. High performance hydrogen/bromine redox flow battery for grid-scale energy storage. J. Electrochem. Soc., 159(11):A1806A1815, 2012.

[9] K. T. Cho, P. Albertus, V. Battaglia, A. Kojic, V. Srinivasan, and A. Z. Weber. Optimization and analysis of high-power hydrogen/bromine-flow batteries for grid-scale energy storage. Energy Technology, 1(10):596-608, 2013.

[10] N. Pekula, K. Heller, P. A. Chuang, A. Turhan, M. M. Mench, J. S. Brenizer, and K. Ünlü. Study of water distribution and transport in a polymer electrolyte fuel cell using neutron imaging. Nuclear Instruments $\&$ Methods In Physics Research A, 542(1-3):134-141, 2005.

[11] A. Z. Weber, R. Balliet, H. P. Gunterman, and J. Newman. Modeling water management in polymerelectrolyte fuel cells. In Modern Aspects of Electrochemistry, number 43, pages 273-415. Springer, New York, 2009.

[12] A. Z. Weber, S. Balasubramanian, and P. K. Das. Proton exchange membrane fuel cells. In Advances in Chemical Engineering: Fuel Cell Engineering, volume 41, pages 66-143. Elsevier, 2012.

[13] S. Um, C. Y. Wang, and K. S. Chen. Computational fluid dynamics modeling of proton exchange fuel cells. J. Electrochem. Soc., 147(12):4485-4493, 2000. 
[14] T. Berning and N. Djilali. A 3D multiphase, multicomponent model of the cathode and anode of a PEM fuel cell. J. Electrochem. Soc., 150(12):A1589-A1598, 2003.

[15] K. W. Lum and J. J. McGuirk. 2D and 3D modeling of a PEMFC cathode with interdigitated gas distributors. J. Electrochem. Soc., 152(4):A811-A817, 2005.

[16] D. H. Schwarz and N. Djilali. 3D modeling of catalyst layers in PEM fuel cells. J. Electrochem. Soc., 154(11):B1167-B1178, 2007.

[17] E. U. Ubong, Z. Shi, and X. Wang. Three-dimensional modeling and experimental study of a high temperature PBI-based PEM fuel cell. J. Electrochem. Soc., 156(10):B1276-B1282, 2009.

[18] R. M. Darling and P. Badrinarayanan. Oxygen transport in polymer-electrolyte fuel cells with interdigitated air channels in porous bipolar plates. J. Electrochem. Soc., 158(1):B54-B60, 2011.

[19] W.-M. Yan, H.-Y. Li, and W.-C. Tsai. Three-dimensional analysis of PEMFCs with different flow channel designs. J. Electrochem. Soc., 153(10):A1984-A1991, 2006.

[20] C.-H. Huang and J.-W. Lin. Optimal gas channel shape design for a serpentine PEMFC: theoretical and experimental studies. J. Electrochem. Soc., 156(1):B178-B187, 2009.

[21] P. K. Sinha, C.-Y. Wang, and U. Beuscher. Transport phenomena in elevated temperature PEM fuel cells. J. Electrochem. Soc., 154(1):B106-B116, 2007.

[22] M. Kvesić, U. Reimer, D. Froning, L. Lüke, W. Lehnert, and D. Stolten. 3D modeling of a $200 \mathrm{~cm}^{2}$ HT-PEFC short stack. Int. J. Hydrogen Energy, 37(3):2430-2439, 2012.

[23] F. Liu, M. Kvesic, K. Wippermann, U. Reimer, and W. Lehnert. Effect of spiral flow field design on performance and durability of HT-PEFCs. J. Electrochem. Soc., 160(8):F892-F897, 2013.

[24] A. P. Manso, F. F. Marzo, J. Barranco, X. Garikano, and M. Garmendia Mujika. Influence of geometric parameters of the flow fields on the performance of a PEM fuel cell. A review. Int. J. Hydrogen Energy, $37(20): 15256-15287,2012$.

[25] M. Rychcik and M. Skyllas-Kazacos. Characteristics of a new all-vanadium redox flow battery. J. Power Sources, 22(1):59-67, 1995.

[26] R. S. Yeo and D. T. Chin. A Hydrogen-Bromine cell for energy storage applications. J. Electrochem. Soc., 127(3):549-555, 1980. 
[27] T. Jyothi Latha and S. Jayanti. Hydrodynamic analysis of flow fields for redox flow battery applications. J. Appl. Electrochem, 44(9):995-1006, 2014.

[28] V. E. Brunini, Y.-M. Chiang, and W. C. Carter. Modeling the hydrodynamic and electrochemical efficiency of semi-solid flow batteries. Electrochemica Acta, 69:301-307, 2012.

[29] M. Duduta, B. Ho, V. C. Wood, P Limthongkul, V. E. Brunini, W. C. Carter, and Y. Chiang. Semi-solid lithium rechargeable flow battery. Adv. Energy Materials, 1(4):511-516, 2011.

[30] K. C. Smith, Y.-M. Chiang, and W. C. Carter. Maximizing energetic efficiency in flow batteries utilizing non-newtonian fluids. J. Electrochem. Soc., 161(4):A486-A496, 2014.

[31] R. M. Darling and M. L. Perry. The influence of electrode and channel configurations on flow battery performance. J. Electrochmical Soc., 161(9):A1381-A1387, 2014.

[32] E. Nishikata, T. Ishii, and T. Ohta. Viscosities of aqueous hydrochloric acid solutions, and densities and viscosities of aqueous hydroiodic acid solutions. J. Chem. Engr. Data, 26:254-256, 1981.

[33] T. Isono. Density, viscosity, and electrolytic conductivity of concentrated aqueous electrolyte solutions at several temperatures. J. Chem. Engr. Data, 29(1):45-52, 1984.

[34] G. Oriji, Y. Katayama, and T. Miura. Investigation on $\mathrm{V}(\mathrm{IV}) / \mathrm{V}(\mathrm{V})$ species in a vanadium redox flow battery. Electrochimica Acta, 49(19):3091-3095, 2004.

[35] J. T. Gostick, M. W. Fowler, M. D. Pritzker, M. A. Ioannidis, and L. M. Behra. In-plane and throughplane gas permeability of carbon fiber electrode backing layers. J. Power Sources, 162(1):228-238, 2006.

[36] T.-H. Shih, W. W. Liou, A. Shabbir, Z. Yang, and J. Zhu. A new $k$ - $\epsilon$ eddy viscosity model for high reynolds number turbulent flows. Computers \& Fluids, 24(3):227-238, 1995.

[37] B. E. Launder and D. B. Spalding. The numerical computation of turbulent flows. Computer Methods in Applied Mechanics and Engineering, 3(2):269-289, 1974.

[38] W. P. Jones and B. E. Launder. The prediction of laminarization with a two-equation model of turbulence. Int. J. Heat Mass Transfer, 15(2):301-314, 1972.

[39] Fluent. FLUENT software, Release 12.0. Available from ANSYS Inc., Canonsburg, PA, 2011.

[40] M. Tucker, K. T. Cho, F. B. Spingler, A. Z. Weber, and G. Lin. Impact of membrane characteristics on the performance and cycling of the $\mathrm{Br}_{2} / \mathrm{H}_{2}$ redox flow cell. J. Power Sources, 284(C):212-221, 2015. 
[41] K. T. Cho, M. C. Tucker, M. Ding, P. Ridgway, V. S. Battaglia, and A. Z. Weber. Cyclic performance analysis of Hydrogen/Bromine flow batteries for grid-scale energy storage. ChemPlusChem, 80:402-411, 2015.

[42] K. B. Shyam Prasad, P. V. Suresh, and S. Jayanti. A hydrodynamic network model for interdigitated flow fields. Int. J. Hydrogen Energy, 24(19):8289-8301, 2009.

[43] OpenFOAM: An open source $\mathrm{C}++$ computer program. Available from www.openfoam.org. 


\begin{tabular}{|c|c|c|}
\hline $\begin{array}{c}\text { Flow Field } \\
\text { Design }\end{array}$ & $\begin{array}{c}\text { Flow Rate } \\
{\left[\mathrm{mL} \mathrm{min}{ }^{-1} \mathrm{~cm}^{-2}\right]}\end{array}$ & $\begin{array}{c}\text { Reynolds \# } \\
\text { In Channel }\end{array}$ \\
\hline \hline $10 \mathrm{~cm}^{2}$ serpentine & 1 & 126 \\
\hline $10 \mathrm{~cm}^{2}$ serpentine & 5 & 630 \\
\hline $50 \mathrm{~cm}^{2}$ serpentine & 1 & 157 \\
\hline $50 \mathrm{~cm}^{2}$ serpentine & 5 & 785 \\
\hline $50 \mathrm{~cm}^{2}$ loose idff & 1 & 139 \\
\hline $50 \mathrm{~cm}^{2}$ loose idff & 5 & 695 \\
\hline $50 \mathrm{~cm}^{2}$ tight idff & 1 & 47 \\
\hline $50 \mathrm{~cm}^{2}$ tight idff & 5 & 235 \\
\hline $400 \mathrm{~cm}^{2}$ loose idff & 1 & 333 \\
\hline $400 \mathrm{~cm}^{2}$ loose idff & 5 & 1665 \\
\hline
\end{tabular}

Table 1: Estimated Reynolds numbers in the individual channels of each flow field design. The 'idff' label refers to interdigitated flow field designs. 


\begin{tabular}{|c|c|c|}
\hline $\begin{array}{c}\text { Flow Field } \\
\text { Design }\end{array}$ & $\begin{array}{c}\text { Electrode } \\
\text { Thickness }[\mathrm{mm}]\end{array}$ & $\begin{array}{c}\text { Mesh Cells } \\
{[\text { million] }}\end{array}$ \\
\hline \hline $10 \mathrm{~cm}^{2}$ serpentine & 0.4 & $10.0 / 11.2$ \\
\hline $50 \mathrm{~cm}^{2}$ serpentine & 0.4 & $6.9 / 10.2 / 14.0 / 20.2$ \\
\hline $50 \mathrm{~cm}^{2}$ serpentine & 1.2 & 21.0 \\
\hline $50 \mathrm{~cm}^{2}$ serpentine & 2.4 & 23.4 \\
\hline $50 \mathrm{~cm}^{2}$ loose idff & 0.4 & 5.7 \\
\hline $50 \mathrm{~cm}^{2}$ loose idff & 1.2 & 11.5 \\
\hline $50 \mathrm{~cm}^{2}$ loose idff & 2.4 & 24.1 \\
\hline $50 \mathrm{~cm}^{2}$ tight idff & 0.4 & 23.4 \\
\hline $50 \mathrm{~cm}^{2}$ tight idff & 1.2 & 30.9 \\
\hline $50 \mathrm{~cm}^{2}$ tight idff & 2.4 & 26.9 \\
\hline $400 \mathrm{~cm}^{2}$ loose idff & 0.4 & 35.6 \\
\hline
\end{tabular}

Table 2: Sizes of the half cell meshes. Multiple values indicate cases where the sensitivity of the results to the mesh size was evaluated. 


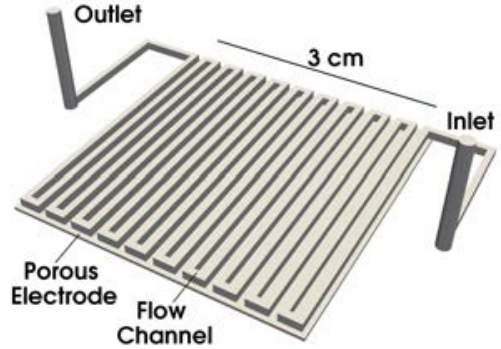

(a) $10 \mathrm{~cm}^{2}$ serpentine, 1 channel

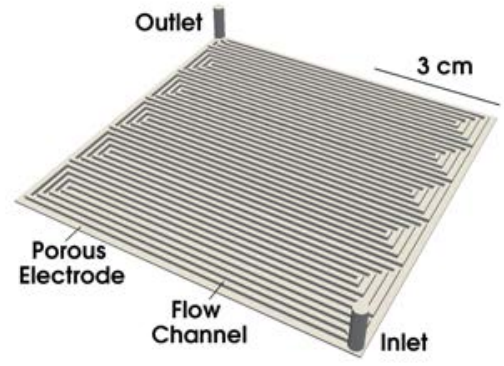

(b) $50 \mathrm{~cm}^{2}$ serpentine, 4 channels

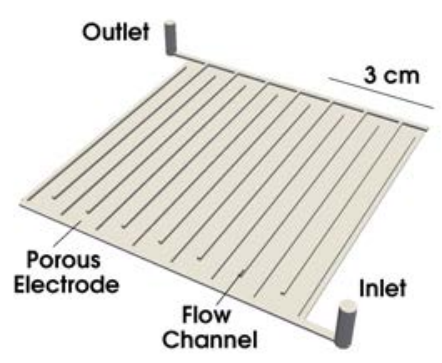

(c) $50 \mathrm{~cm}^{2}$ loose interdigitated

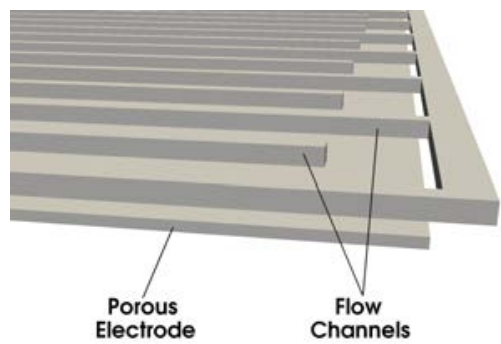

(f) $0.4 \mathrm{~mm}$ electrode

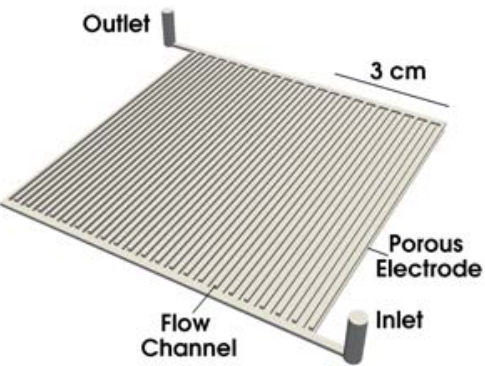

(d) $50 \mathrm{~cm}^{2}$ tight interdigitated

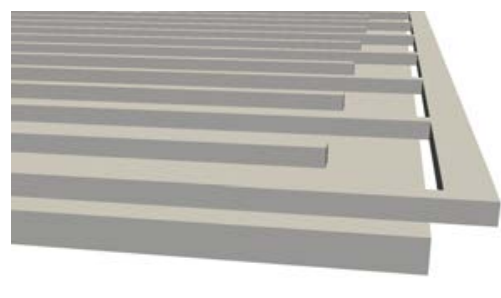

(g) $1.2 \mathrm{~mm}$ electrode

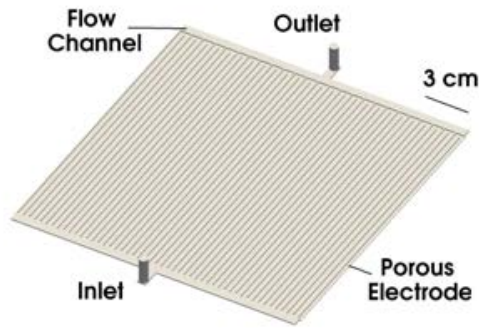

(e) $400 \mathrm{~cm}^{2}$ loose interdigitated

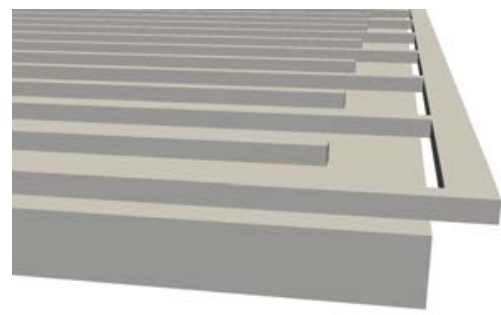

(h) $2.4 \mathrm{~mm}$ electrode

Figure 1: a) - e) Simulated flow battery flow field designs. Inlet and outlet locations in the serpentine cases were chosen to match the hardware from Cho et al. [8, 9]. Inlets and outlets in the $50 \mathrm{~cm}^{2}$ interdigitated cases were chosen to provide consistency with the $50 \mathrm{~cm}^{2}$ serpentine design, while in the $400 \mathrm{~cm}^{2}$ case a more symmetric inlet and outlet configuration was used. f) - h) Comparison of electrode thicknesses, shown using the $50 \mathrm{~cm}^{2}$ loose interdigitated flow field. 


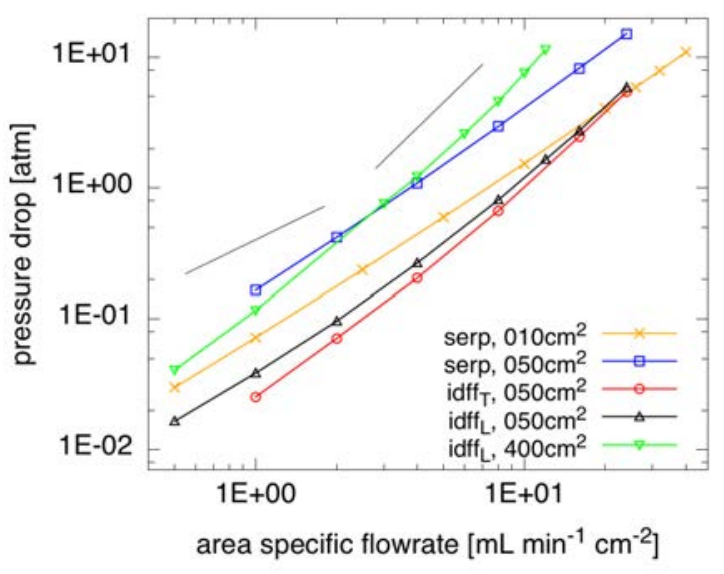

(a) Pressure losses for $0.4 \mathrm{~mm}$ electrodes. The thin black lines are linear and quadratic scaling curves.

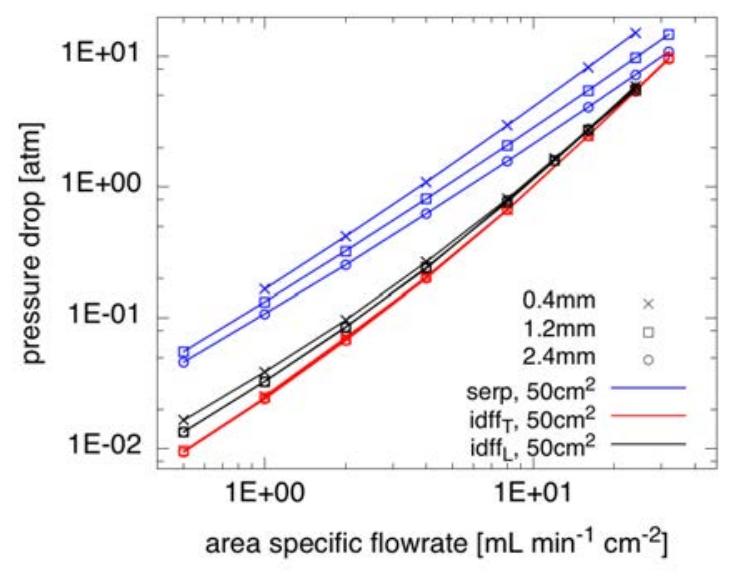

(b) Pressure loss vs. electrode thickness.

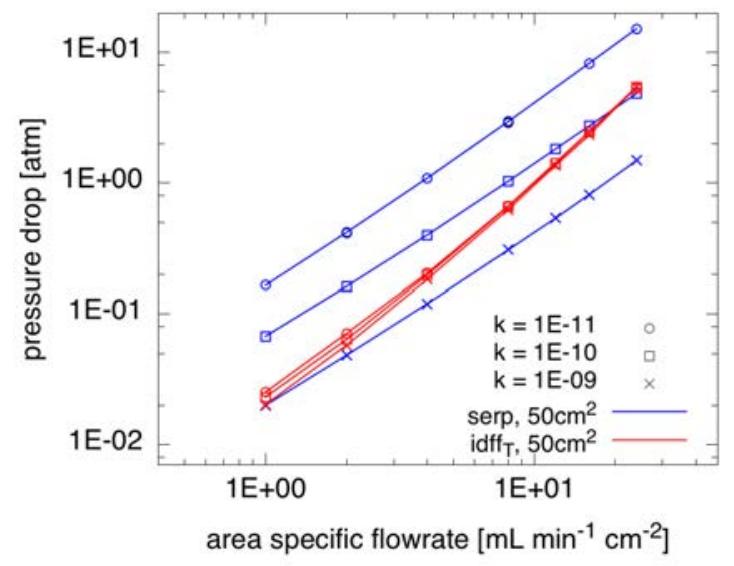

(c) Pressure loss vs. electrode permeability.

Figure 2: Pressure drops across one half of the flow battery system, calculated as a function of active cell area, cell design, electrode thickness, electrode permeability, and flow rate. The ' $T$ ' and ' $L$ ' subscripts refer to the tight and loose interdigitated flow channel spacings, respectively. 


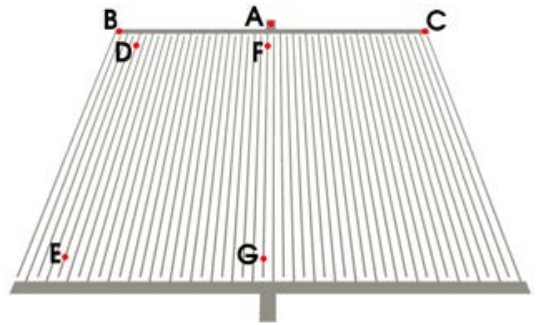

(a) Pressure tap locations.

\begin{tabular}{|c|c|c|}
\hline $\begin{array}{c}\text { Flow } \\
\text { Pathway }\end{array}$ & $\begin{array}{c}\text { Pressure } \\
\text { Drop [atm] }\end{array}$ & $\begin{array}{c}\text { Pressure Drop } \\
\text { [\% of total] }\end{array}$ \\
\hline \hline $\mathrm{A} \rightarrow \mathrm{B}$ & 1.89 & $25 \%$ \\
\hline $\mathrm{A} \rightarrow \mathrm{C}$ & 1.95 & $26 \%$ \\
\hline $\mathrm{A} \rightarrow \mathrm{F}$ & 1.88 & $25 \%$ \\
\hline $\mathrm{D} \rightarrow \mathrm{E}$ & 0.61 & $8 \%$ \\
\hline $\mathrm{F} \rightarrow \mathrm{G}$ & 1.28 & $17 \%$ \\
\hline
\end{tabular}

(b) Pressure drop magnitudes.

Figure 3: Pressure drops across flow pathways from a plane cut through the open flow channels of the 400 $\mathrm{cm}^{2}$ loose interdigitated design. The flow rate is $10 \mathrm{~mL} \mathrm{~min}-1 \mathrm{~cm}^{-2}$ and the slice is taken halfway up the open channels. Point A represents the inlet, and the total pressure drop is $7.57 \mathrm{~atm}$. 


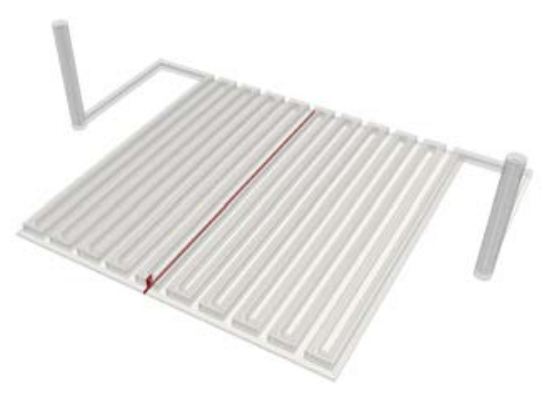

(a) Plane where data is extracted from the $10 \mathrm{~cm}^{2}$ serpentine design.

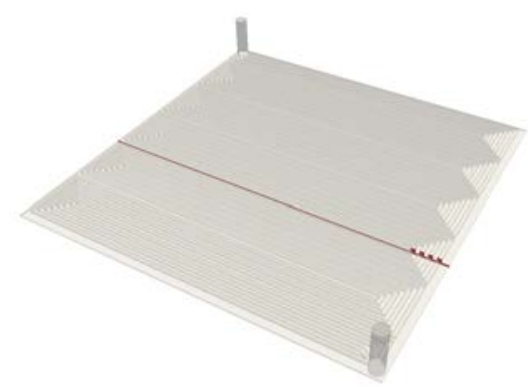

(b) Plane where flux data is extracted from the $50 \mathrm{~cm}^{2}$ serpentine design.

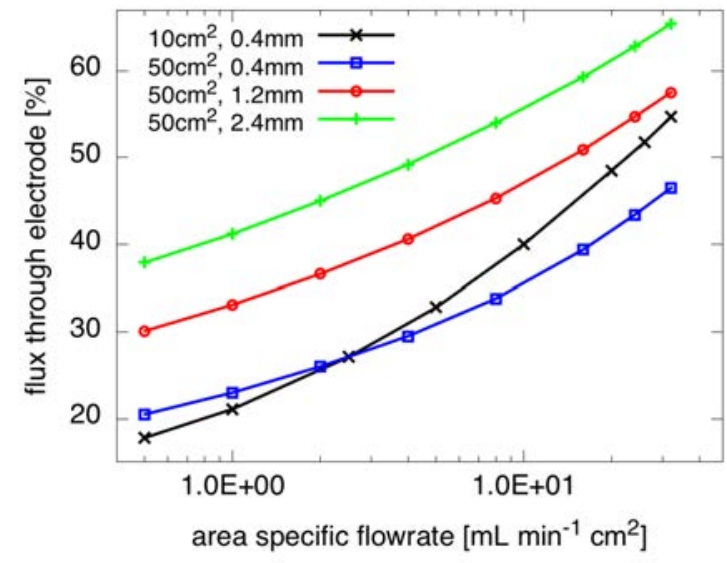

(c) Percentage of the total normal flux passing through the electrode.

Figure 4: Percentage of the total normal flux that passes through the electrode in serpentine flow field designs. The remainder of the normal flux passes through the open flow channels. 


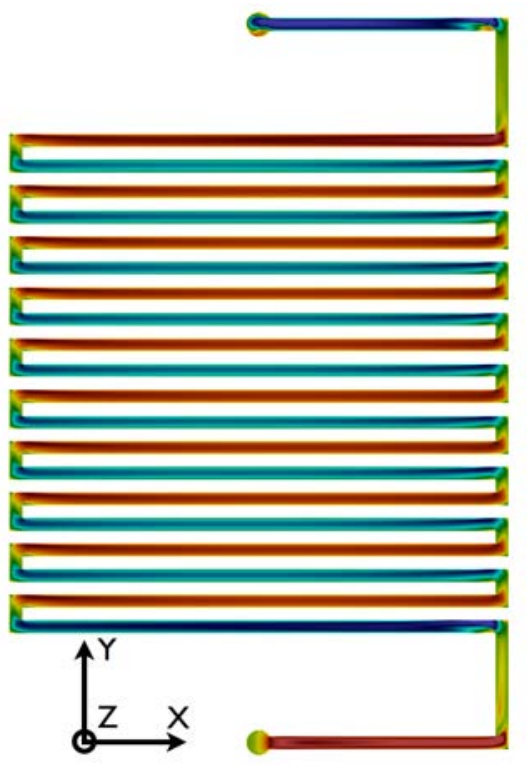

(a) $\mathrm{x}$ velocity $\left[\mathrm{m} \mathrm{s}^{-1}\right]$
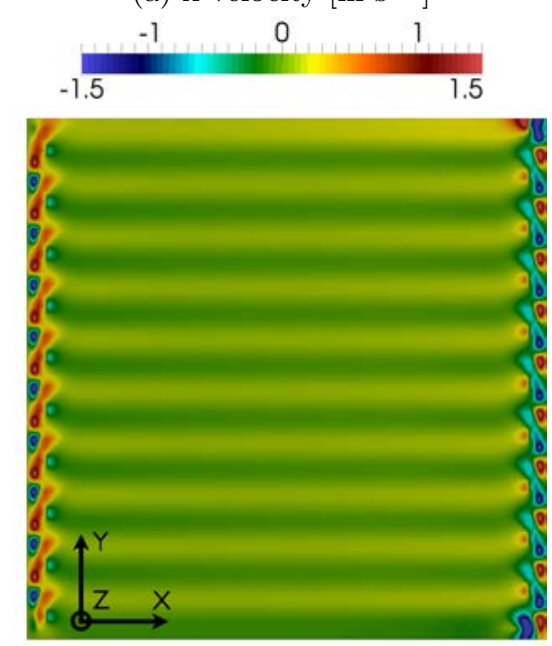

(d) $\mathrm{x}$ velocity $\left[\mathrm{m} \mathrm{s}^{-1}\right]$

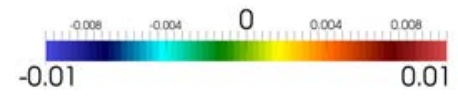

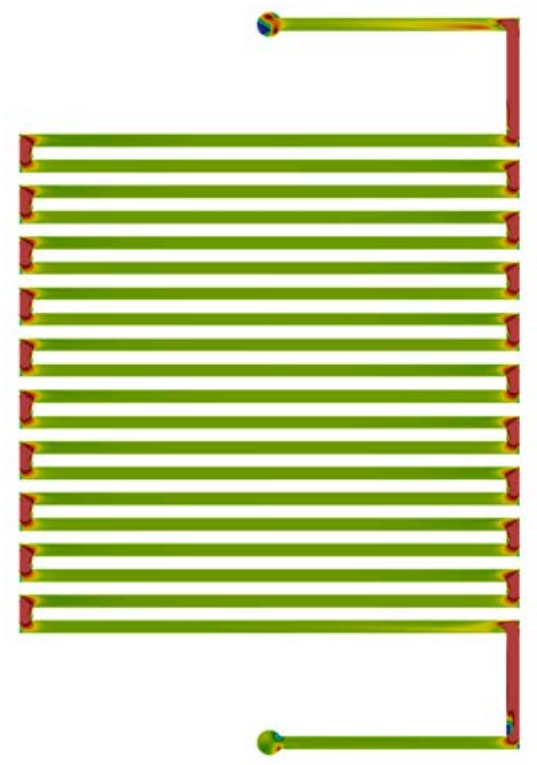

(b) y velocity $\left[\mathrm{m} \mathrm{s}^{-1}\right]$
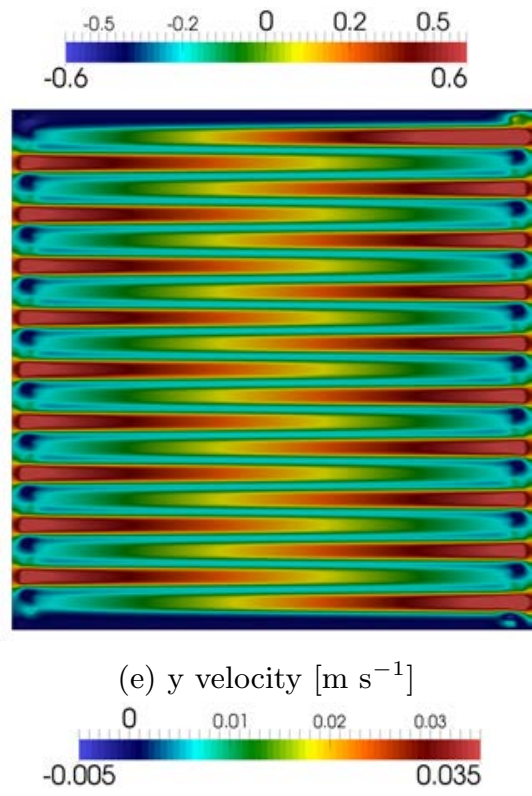

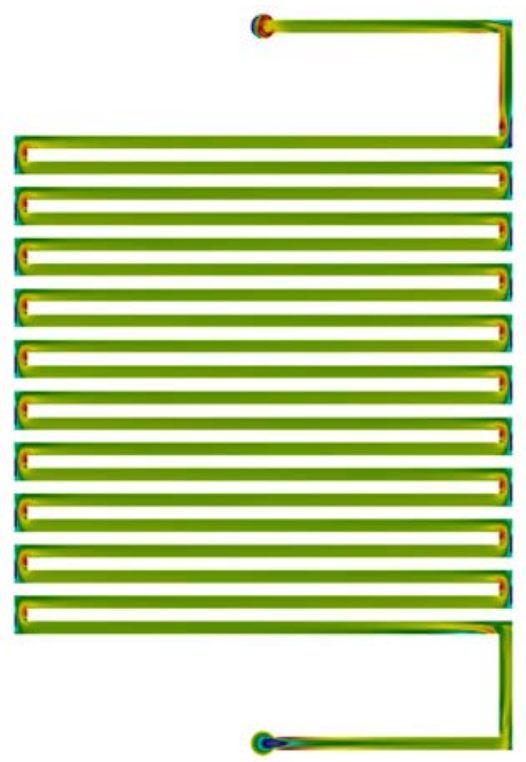

(c) z velocity $\left[\mathrm{m} \mathrm{s}^{-1}\right]$
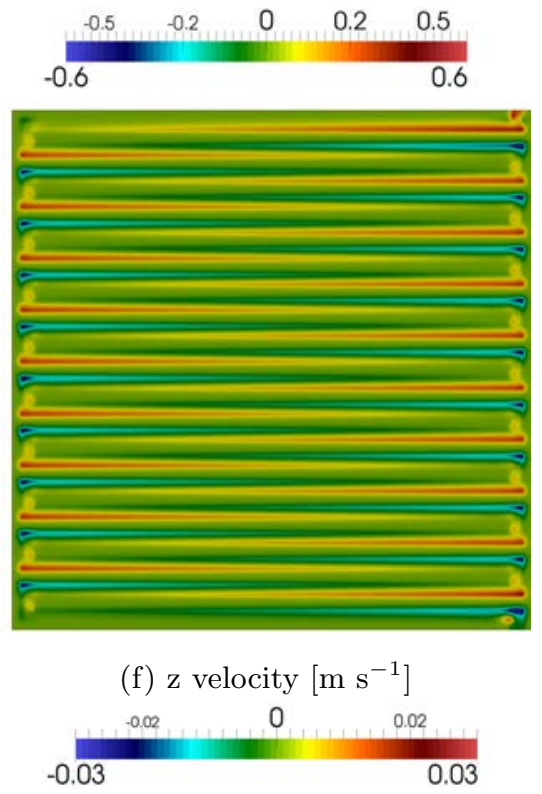

Figure 5: Velocity contour plots from a $10 \mathrm{~cm}^{2}$ single channel serpentine flow field with a $0.4 \mathrm{~mm}$ electrode, at a flow rate of $5 \mathrm{~mL} \mathrm{~min}{ }^{-1} \mathrm{~cm}^{-2}$. Figures $5 \mathrm{a}-5 \mathrm{c}$ show a cut halfway $(0.4 \mathrm{~mm})$ through the depth of the flow channels, while Figures $5 \mathrm{~d}-5 \mathrm{f}$ show a cut halfway $(0.2 \mathrm{~mm})$ through the depth of the electrode. 


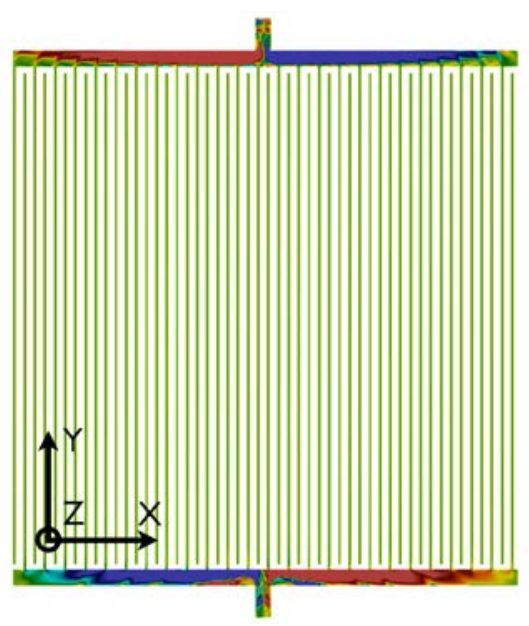

(a) $\mathrm{x}$ velocity $\left[\mathrm{m} \mathrm{s}^{-1}\right]$
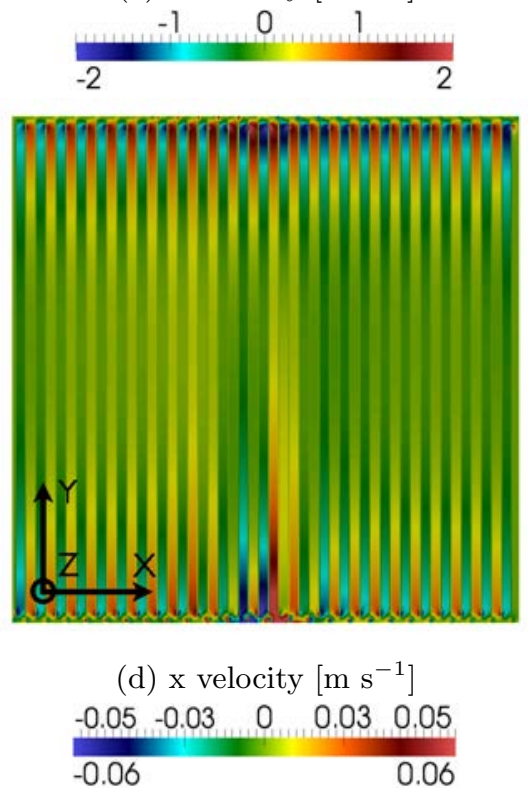

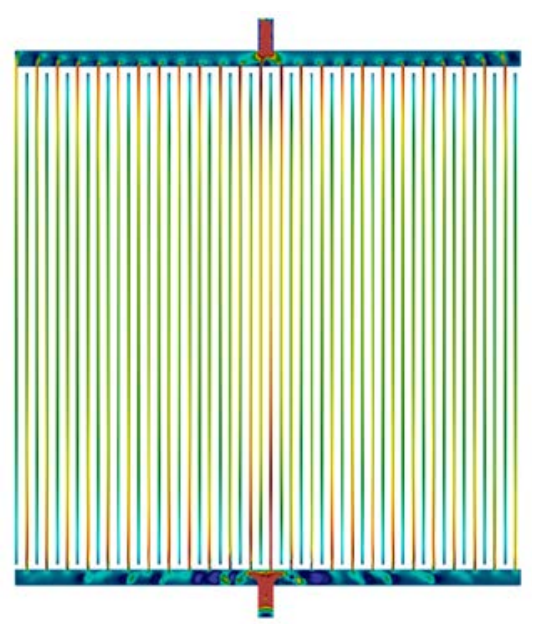

(b) y velocity $\left[\mathrm{m} \mathrm{s}^{-1}\right]$

$0-2$
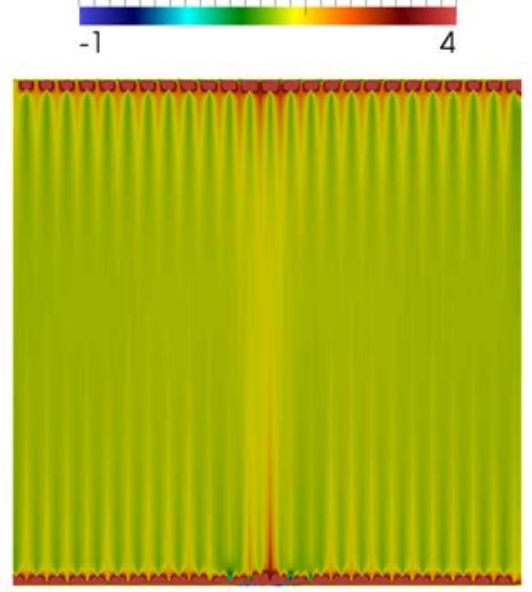

(e) y velocity $\left[\mathrm{m} \mathrm{s}^{-1}\right]$

$\begin{array}{lll}-0.01 & 0 & 0.01 \\ -0.02 & 0.02\end{array}$

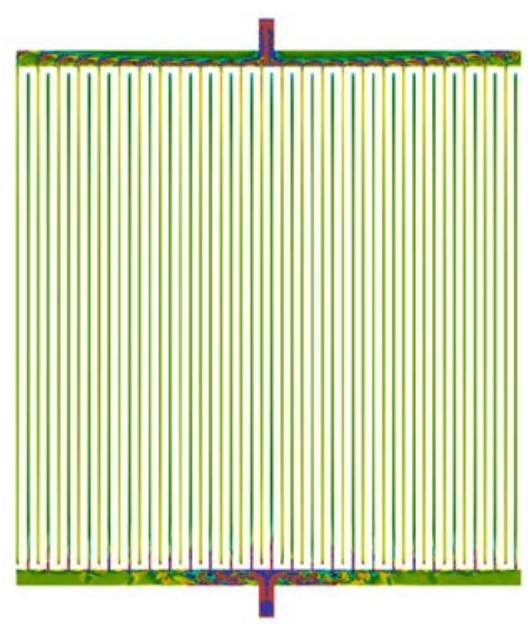

(c) $\mathrm{z}$ velocity $\left[\mathrm{m} \mathrm{s}^{-1}\right]$ $\begin{array}{llllll}-0.08 & -0.04 & 0 & 0.04 & 0.08\end{array}$ $\begin{array}{ll}-0.1 & 0.1\end{array}$

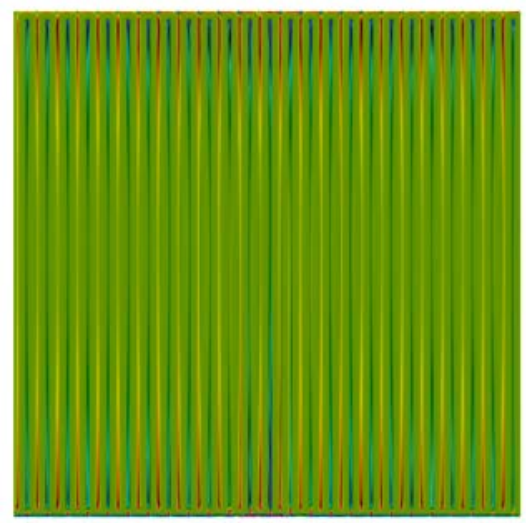

$$
\begin{aligned}
& \text { (f) } \mathrm{z} \text { velocity }\left[\mathrm{m} \mathrm{s}^{-1}\right] \\
& \begin{array}{lll}
-0.01 & 0 & 0.01
\end{array} \\
& \begin{array}{ll}
-0.02 & 0.02
\end{array}
\end{aligned}
$$

Figure 6: Velocity contour plots from a $400 \mathrm{~cm}^{2}$ loose interdigitated flow field with a 0.4 mm electrode, at a flow rate of $6 \mathrm{~mL} \mathrm{~min}^{-1} \mathrm{~cm}^{-2}$. Figures $6 \mathrm{a}-6 \mathrm{c}$ show a cut halfway $(0.4 \mathrm{~mm})$ through the depth of the flow channels, while Figures $6 \mathrm{~d}$ - 6 f show a cut halfway $(0.2 \mathrm{~mm})$ through the depth of the electrode. 


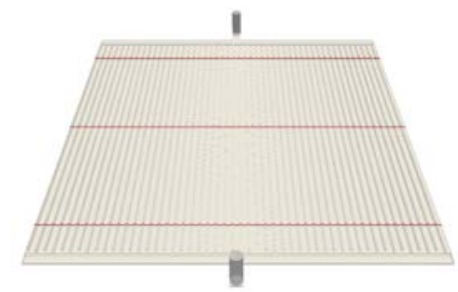

(a) Cut plane locations; velocity contours are shown only for the middle sections of these planes.

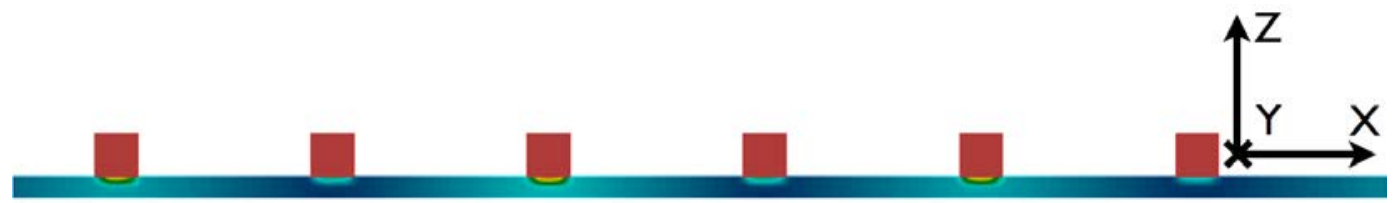

(b) y velocity $\left[\mathrm{m} \mathrm{s}^{-1}\right]$, near inlet

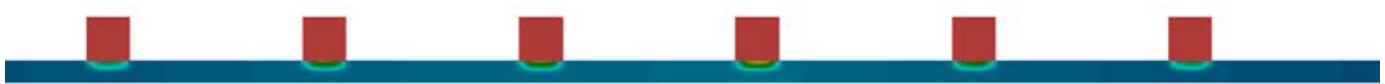

(c) y velocity $\left[\mathrm{m} \mathrm{s}^{-1}\right]$, near middle

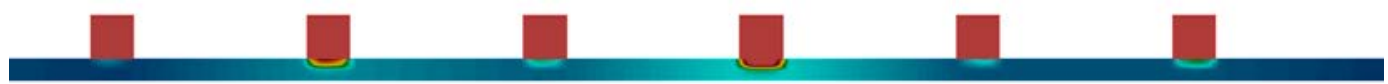

(d) y velocity $\left[\mathrm{m} \mathrm{s}^{-1}\right]$, near outlet

$$
\begin{array}{lllll}
0 & 0.025 & 0.05 & 0.075
\end{array}
$$
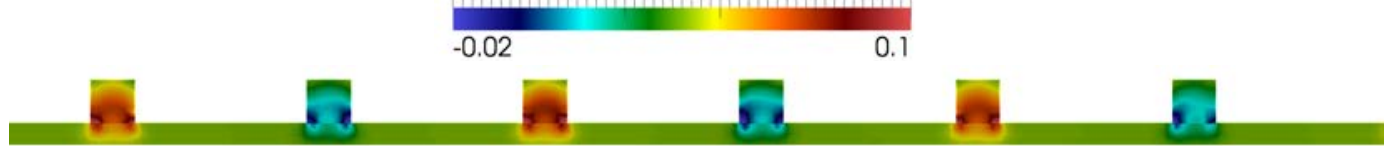

(e) z velocity $\left[\mathrm{m} \mathrm{s}^{-1}\right]$, near inlet

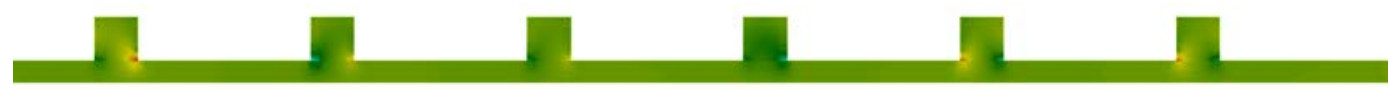

(f) $\mathrm{z}$ velocity $\left[\mathrm{m} \mathrm{s}^{-1}\right]$, near middle

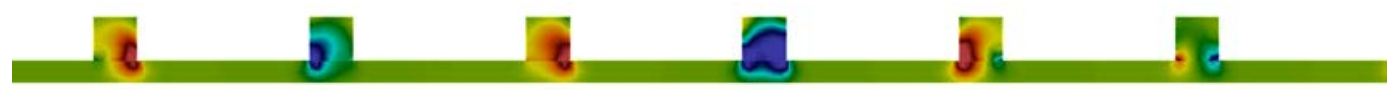

(g) z velocity $\left[\mathrm{m} \mathrm{s}^{-1}\right]$, near outlet

$\begin{array}{lllll}-0.05 & -0.03 & 0 & 0.025 & 0.05\end{array}$

$-0.06-0.06$

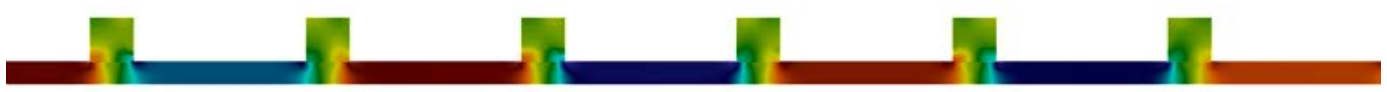

(h) $\mathrm{x}$ velocity $\left[\mathrm{m} \mathrm{s}^{-1}\right]$, near inlet

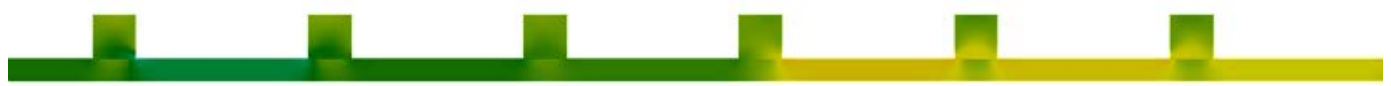

(i) $\mathrm{x}$ velocity $\left[\mathrm{m} \mathrm{s}^{-1}\right]$, near middle

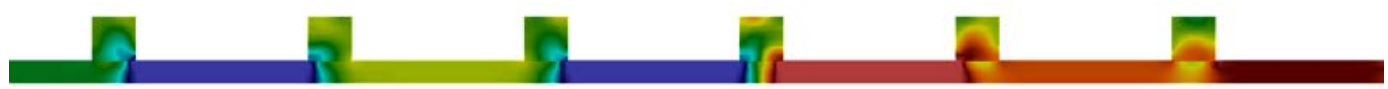

(j) x velocity $\left[\mathrm{m} \mathrm{s}^{-1}\right]$, near outlet

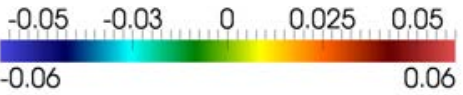

Figure 7: Velocity contours from the $400 \mathrm{~cm}^{2}$ loose interdigitated design for a flow rate of $10 \mathrm{~mL} \mathrm{~min} \mathrm{~cm}^{-1}$. 


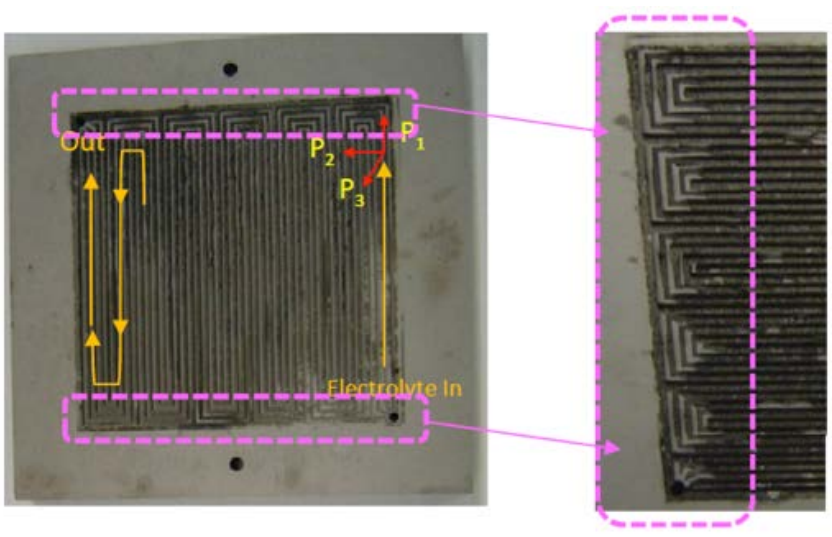

(a) Experimental observation

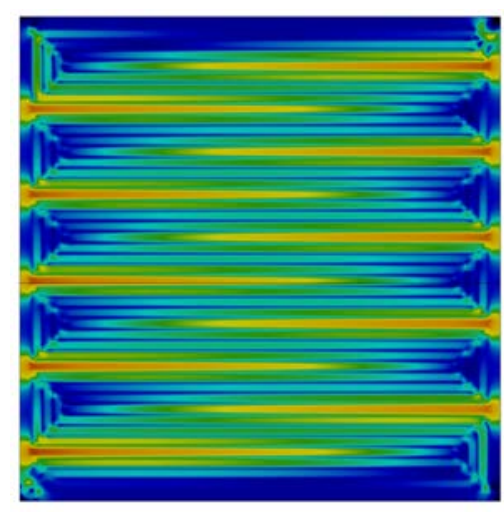

(b) velocity magnitude $\left[\mathrm{m} \mathrm{s}^{-1}\right]$ $1.0 \mathrm{E}-03$ 1.0E-02

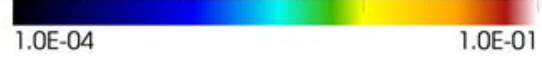

Figure 8: a) Degradation example from a $50 \mathrm{~cm}^{2} \mathrm{H}_{2} / \mathrm{Br}_{2}$ serpentine flow battery cell operated at $60 \mathrm{~mA} \mathrm{~cm}^{-2}$ for 100 hours between cutoff potentials of $1.25 \mathrm{~V}$ and $0.80 \mathrm{~V}$. More degradation occurred around the bends of the flow channels. These images are previously unpublished results from the experiments reported by Cho et al. [8, 9]. b) Velocity magnitudes in a cut plane located $0.3 \mathrm{~mm}$ (75\% of the electrode thickness) below the flow channel / electrode interface, taken from a $50 \mathrm{~cm}^{2}$ serpentine, $0.4 \mathrm{~mm}$ electrode case with a flow rate of $2 \mathrm{~mL} \mathrm{~min}^{-1} \mathrm{~cm}^{-2}$ to match approximately the flow rate from the experiments in Fig. 8a. 


\section{List of Tables}

1 Estimated Reynolds numbers in the individual channels of each flow field design. The 'idff' label refers to interdigitated flow field designs. . . . . . . . . . . . . . . . . . . . 19

2 Sizes of the half cell meshes. Multiple values indicate cases where the sensitivity of the results to the mesh size was evaluated. $\ldots \ldots \ldots \ldots \ldots \ldots \ldots \ldots$ 


\section{List of Figures}

1 a) - e) Simulated flow battery flow field designs. Inlet and outlet locations in the serpentine cases were chosen to match the hardware from Cho et al. $[8,9]$. Inlets and outlets in the $50 \mathrm{~cm}^{2}$ interdigitated cases were chosen to provide consistency with the $50 \mathrm{~cm}^{2}$ serpentine design, while in the $400 \mathrm{~cm}^{2}$ case a more symmetric inlet and outlet configuration was used. f) - h) Comparison of electrode thicknesses, shown using the $50 \mathrm{~cm}^{2}$ loose interdigitated flow

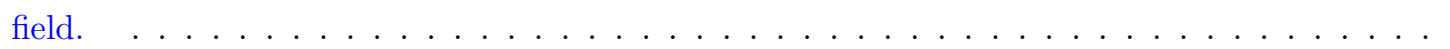

2 Pressure drops across one half of the flow battery system, calculated as a function of active cell area, cell design, electrode thickness, electrode permeability, and flow rate. The ' $T$ ' and 'L' subscripts refer to the tight and loose interdigitated flow channel spacings, respectively. .

3 Pressure drops across flow pathways from a plane cut through the open flow channels of the

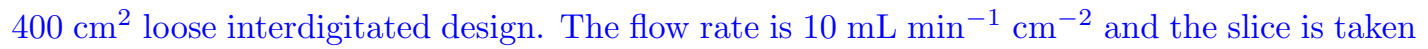
halfway up the open channels. Point A represents the inlet, and the total pressure drop is

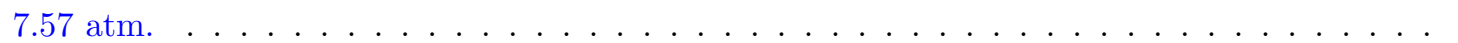

4 Percentage of the total normal flux that passes through the electrode in serpentine flow field designs. The remainder of the normal flux passes through the open flow channels. . . . . . .

5 Velocity contour plots from a $10 \mathrm{~cm}^{2}$ single channel serpentine flow field with a $0.4 \mathrm{~mm}$

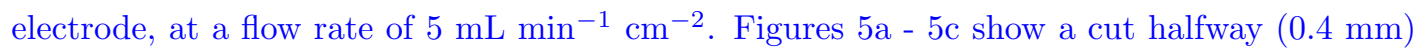
through the depth of the flow channels, while Figures $5 \mathrm{~d}-5 \mathrm{f}$ show a cut halfway $(0.2 \mathrm{~mm})$

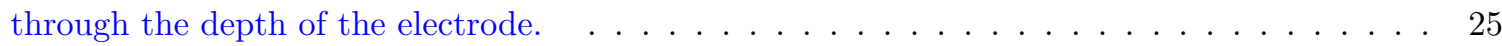

6 Velocity contour plots from a $400 \mathrm{~cm}^{2}$ loose interdigitated flow field with a $0.4 \mathrm{~mm}$ electrode, at a flow rate of $6 \mathrm{~mL} \mathrm{~min}{ }^{-1} \mathrm{~cm}^{-2}$. Figures $6 \mathrm{a}-6 \mathrm{c}$ show a cut halfway $(0.4 \mathrm{~mm})$ through the depth of the flow channels, while Figures $6 \mathrm{~d}-6 \mathrm{f}$ show a cut halfway $(0.2 \mathrm{~mm})$ through the

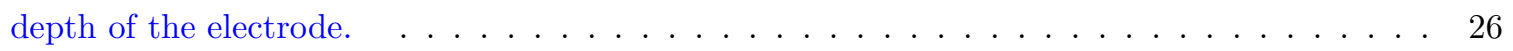

7 Velocity contours from the $400 \mathrm{~cm}^{2}$ loose interdigitated design for a flow rate of $10 \mathrm{~mL} \mathrm{~min} \mathrm{~cm}^{-1}$. 
8 a) Degradation example from a $50 \mathrm{~cm}^{2} \mathrm{H}_{2} / \mathrm{Br}_{2}$ serpentine flow battery cell operated at $60 \mathrm{~mA} \mathrm{~cm}^{-2}$ for 100 hours between cutoff potentials of $1.25 \mathrm{~V}$ and $0.80 \mathrm{~V}$. More degradation occurred around the bends of the flow channels. These images are previously unpublished results from the experiments reported by Cho et al. $[8,9]$. b) Velocity magnitudes in a cut plane located $0.3 \mathrm{~mm}$ (75\% of the electrode thickness) below the flow channel / electrode interface, taken from a $50 \mathrm{~cm}^{2}$ serpentine, $0.4 \mathrm{~mm}$ electrode case with a flow rate of $2 \mathrm{~mL} \mathrm{~min} \mathrm{~m}^{-1} \mathrm{~cm}^{-2}$ to match approximately the flow rate from the experiments in Fig. 8a. . . . . . . . . . 28 